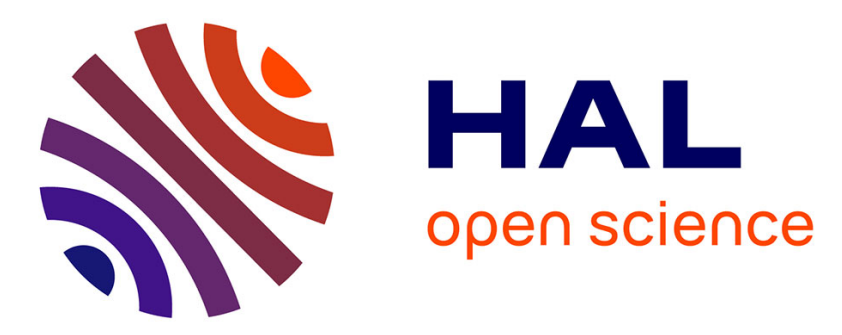

\title{
Small molecule-based photocrosslinkable fluorescent materials toward multilayered and high-resolution emissive patterning
}

Simon Olivier, Lionel Derue, Bernard Geffroy, Tony Maindron, Eléna Ishow

\section{To cite this version:}

Simon Olivier, Lionel Derue, Bernard Geffroy, Tony Maindron, Eléna Ishow. Small molecule-based photocrosslinkable fluorescent materials toward multilayered and high-resolution emissive patterning. Journal of Materials Chemistry, 2015, 3, pp.8403-8412. 10.1039/c5tc01453k . cea-01252700

\author{
HAL Id: cea-01252700 \\ https://hal-cea.archives-ouvertes.fr/cea-01252700
}

Submitted on 8 Jan 2016

HAL is a multi-disciplinary open access archive for the deposit and dissemination of scientific research documents, whether they are published or not. The documents may come from teaching and research institutions in France or abroad, or from public or private research centers.
L'archive ouverte pluridisciplinaire HAL, est destinée au dépôt et à la diffusion de documents scientifiques de niveau recherche, publiés ou non, émanant des établissements d'enseignement et de recherche français ou étrangers, des laboratoires publics ou privés. 


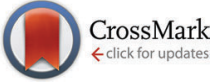

Cite this: J. Mater. Chem. C, 2015, 3, 8403

\section{Small molecule-based photocrosslinkable fluorescent materials toward multilayered and high-resolution emissive patterning $\dagger$}

\author{
Simon Olivier, ${ }^{\mathrm{ab}}$ Lionel Derue, $^{\mathrm{cd}}$ Bernard Geffroy, $^{\mathrm{cd}}$ Tony Maindron $^{\mathrm{b}}$ and \\ Eléna Ishow ${ }^{* a}$
}

\begin{abstract}
Solution-processable green and red-emitting fluorophores possessing photopolymerizable acrylate units have been synthesized. Photocrosslinking was successfully performed in neat thin films at room temperature under low-dose UV irradiation at $365 \mathrm{~nm}$. No further curing step was necessary to achieve insoluble emissive thin films displaying high optical quality. Up to $80 \%$ of the green emitting material processed as a non-doped thin film remained after photopolymerization. Despite competitive energy transfer occurring between the excited photoinitiator and the radiative excited state of red-emitting materials, up to $40 \%$ of the initial thickness could be achieved after development. The very low RMS roughness of the green and red photocrosslinked thin films after development (RMS $<0.7 \mathrm{~nm}$ ) allowed us to fabricate multicolored stacks again with high optical quality (RMS roughness $<1.3 \mathrm{~nm}$ ) after two cycles of irradiation and development involving successively red and green emitters. Resolved patterns as small as $600 \mathrm{~nm}$ in width could be obtained upon photolithography performed under an air atmosphere. High adhesion of the photocrosslinked materials on surfaces makes the resulting emissive thin films very promising for realizing complex emissive structures on flat or bend substrates as required in multiple applications such as optical data storage, organic lasers, organic light emitting diodes or counterfeiting.
\end{abstract}

Received 21st May 2015, Accepted 14th July 2015 DOI: $10.1039 / c 5 t c 01453 k$ www.rsc.org/MaterialsC of photopolymerizable thin layers through a shadow mask, followed by a simple development step to remove the soluble non-polymerized material. Most of the current patternable emissive materials involve photocrosslinkable polymers or sol-gel matrices that are doped with organic entities (fluorophores, quantum dots) and a low amount of photosensitizers. ${ }^{7}$ They usually involve acrylate or oxetane monomers that yield insoluble patterns after illumination and a simple development step. Alternatively, photochromic molecules mixed with fluorophores within a polymeric matrix can be exploited to generate reversible fluorescent patterns after one-photon ${ }^{1 a, 8}$ or two-photon illumination $^{1 b}$ due to efficient energy transfer from the fluorophores to the newly formed photoisomers. Yet, in both cases, large structural differences between the dispersed dyes and the surrounding matrices lead to progressive phase segregation over time due to dye diffusion or polymer chain reorganization, resulting in diminished performances. Moreover, high concentrations of fluorophores dissolved in the stock materials are usually prohibited to avoid $\pi-\pi$ stacking and microaggregates that cause optical losses upon light scattering or strong emission quenching upon dark state formation. Surprisingly, very few organic systems displaying fluorophores covalently attached to photopolymerizable monomer units have been developed to date, although dye-grafted polymers compared to dye-doped ones have 
proved to display higher structural stability and composition. ${ }^{9} \mathrm{We}$ suspect that the quite recent emergence of bulk emissive organic materials and the possibility of deleterious competing photoreactions between the photoreactive units and fluorophores have represented serious obstacles to the development of neat glassy photopolymerizable fluorescent materials. ${ }^{10}$ In this context, the first photopolymerizable emissive organic materials reported in the literature involved semi-conjugated spirobifluorene-co-fluorene copolymers $^{4,11}$ or dye-grafted copolymers ${ }^{12}$ whose photocrosslinking was permitted by peripheral photoreactive units (oxetane or coumarin). Although the adopted strategy was successfully applied to the fabrication of insoluble emissive patterns for organic light emitting diodes or data storage, the emission color and intensity depended on the copolymer chain geometry and composition whose high reproducibility is difficult to achieve. To address these structural limitations, the development of small molecule-based crosslinkable styrenyl systems has been proposed, based on luminescent iridium complexes whose geometry and emission color are perfectly defined. ${ }^{13}$ However, thermal crosslinking at high temperatures $\left(180^{\circ} \mathrm{C}\right)$ was employed, which limits the use of such materials to flat surfaces or fragile substrates for cryptography applications. Moreover, dilution of the emitters was systematically performed, requiring a delicate choice of the host in terms of photophysical, electronic and mechanical properties. In order to respond to the lack of small moleculebased photocrosslinkable materials requiring no further heat treatment, we report herein on an innovative series of fluorophores substituted with acrylate monomers. The latter can be processed as neat films with no need of stabilizing matrices. They form highly emissive insoluble patterns after photoirradiation and development. Photolithography allowed us to obtain resolved features as small as $600 \mathrm{~nm}$ in width. We believe that small functional molecule-based photopolymerizable precursors, thanks to their unique molecular structure, will soon represent very attractive active materials toward photopatterning of solution-processed thin layers. ${ }^{14}$ Such a route appears indeed very versatile and applicable to various applications requiring the structured deposition of little amount of emissive material while keeping strongly and easily detectable fluorescent signals.

\section{Results and discussion}

\section{Modular synthetic strategy}

We developed in the past a series of fluorescent materials based on push-pull triarylamines containing bulky substituents to discard notable $\pi-\pi$ stacking and enable high emission in the solid state. ${ }^{15}$ We thus kept the same generic backbone where emission color can simply be tuned by the charge transfer magnitude, and introduced photopolymerizable units on the peripheral branches. Acrylate units instead of methacrylate ones were chosen as photopolymerizable monomers as they exhibit higher photoreactivity. In this way, overexposure of the fluorescent materials and associated photodamages is avoided. Both acrylate monomers were placed far apart to rule out any intramolecular cross-linking. Here, the choice of the linker between the fluorescent core and the photocrosslinking units is very important in terms of mechanical and thermal properties. In the present case, fabricating small molecule-based materials with glass transition temperature close to room temperature is an absolute prerequisite to favor photoreaction in the absence of heating. We actually demonstrated that the glass transition temperatures of small molecule-based materials directly correlated to the bulkiness and flexibility of the triphenylarylamine peripheral substituents. ${ }^{16}$ We thus chose ethyleneoxy chains instead of alkyl ones to provide enough fluidity in thin films, hence efficient photoreactivity of the acrylate units is expected in the absence of a solvent. Finally, the saturated nature of the linker revealed to be essential to efficiently impair through-bond energy transfer between the fluorescent and the photopolymerizable units. We adopted the following modular synthetic strategy as depicted in Scheme 1 to obtain the targeted molecules (Scheme 1).

Two emissive monomers 7 and $\mathbf{8}$, emitting in the green and the red regions of the visible spectrum, respectively, could be obtained using the same benzylic key intermediate 4. Compound 4 was obtained after deprotection of the protected benzyl alcohol derivative 3 produced from a Suzuki cross coupling between 4-di(4-bromophenyl)aminobenzaldehyde synthesized using a literature procedure, ${ }^{15}$ and arylboronic acid 2 formed in two steps. Knoevenagel condensation with malononitrile to generate the red-emitting precursor 5 was carried out on compound 4 and not earlier to save synthetic efforts and avoid above all nucleophilic 1,4-addition that would disrupt the charge transfer. Introduction of the photopolymerizable units was eventually performed in the final step to reduce the risks of undesirable polymerization. Mild Steglich esterification conditions between the diol derivatives $\mathbf{4}$ or $\mathbf{5}$ and the dicarboxylic acid derivative $\mathbf{6}$, obtained from a quantitative reaction between succinic anhydride and 2-hydroxyethylacrylate, provided the final compounds 7 and $\mathbf{8}$ in good yields (63-64\%). Such a pathway eliminates the risks of untractable polycondensation and low reaction yields that would occur if succinic anhydride and 2-hydroxyethylacrylate were successively reacted with $\mathbf{4}$ or $\mathbf{5}$.

\section{Glassy behavior and fluorescence properties}

Both compounds 7 and $\mathbf{8}$ exhibit glass transition temperatures $T_{\mathrm{g}}$ at around $6.4{ }^{\circ} \mathrm{C}$ and $11.9^{\circ} \mathrm{C}$, respectively, as detected by differential scanning calorimetry over the temperature range $[-30 ; 140]{ }^{\circ} \mathrm{C}$ after a first heating-cooling cycle to erase the sample history (Table 1 ; see ESI, $\dagger$ Fig. S1). No peak crystallization was observed as a consequence of the racemic mixture for 7 and 8, providing additional disorder. These unexpectedly low $T_{\mathrm{g}}$ values are directly connected to the acrylate linkers since similar compounds with peripheral tert-butyl groups display $T_{\mathrm{g}}$ values above $80{ }^{\circ} \mathrm{C} .{ }^{15}$ The viscous state of the material advantageously favors extensive photoreactivity of the acrylate units linked to mobile ethylenoxy chains, and great filmogenicity of the monomer solutions (1-2 wt $\%$ in chloroform), yielding very homogeneous thin films after deposition on pre-cleaned glass substrates or silicon wafers (see infra).

The UV-vis absorption spectra of monomers 7 and $\mathbf{8}$ display very similar features in toluene solution and thin films, namely 
<smiles>CCOC(C)c1ccc(-c2ccc(N(c3ccc(C=O)cc3)c3ccc(-c4ccc(C(C)OCC)cc4)cc3)cc2)cc1</smiles><smiles>C=CC(=O)OCCOC(=O)CCC(=O)OCCOC(=O)CCC(=O)OC(C)c1ccc(-c2ccc(N(c3ccc(C(C)=O)cc3)c3ccc(-c4ccc(C(C)OC(=O)CCC(=O)OCCOC(=O)C=C)cc4)cc3)cc2)cc1</smiles>

Scheme 1 Synthetic pathway to photopolymerizable fluorophores 7 and 8. (i) TBDMSCl, dimethylaminopyridine, imidazole, dimethylformamide, RT, $12 \mathrm{~h}, 81 \%$. (ii) $n$-BuLi, $\mathrm{B}(\mathrm{OiPr})_{3}, \mathrm{THF},-80^{\circ} \mathrm{C}, 4 \mathrm{~h}, 97 \%$. (iii) 4-di(4-bromophenyl)aminobenzaldehyde, $\mathrm{P}\left(\mathrm{o}\right.$-tolyl) $3, \mathrm{Pd}(\mathrm{OAc})_{2}, \mathrm{KOH}$, toluene, methanol, $70{ }^{\circ} \mathrm{C}$, $12 \mathrm{~h}, 76 \%$. (iv) TBAF $1 \mathrm{M}, \mathrm{THF}, \mathrm{RT}, 4 \mathrm{~h}, 92 \%$. (v) malononitrile, $\mathrm{AcONH}_{4}, \mathrm{AcOH}$, pyridine, $\mathrm{RT}, 12 \mathrm{~h}, 96 \%$. (vi) Dimethylaminopyridinium $p$-toluenesulfonate (DPTS), DCC, $\mathrm{CH}_{2} \mathrm{Cl}_{2}, \mathrm{O}^{\circ} \mathrm{C} \rightarrow \mathrm{RT}, 12 \mathrm{~h}, 63-64 \%$.

Table 1 Thermal analyses and photophysical properties in solution and thin films

\begin{tabular}{|c|c|c|c|c|c|}
\hline \multirow[b]{2}{*}{ Cpd } & \multirow[b]{2}{*}{$T_{g}^{a}\left({ }^{\circ} \mathrm{C}\right)$} & \multicolumn{2}{|l|}{$\lambda_{\max }^{\mathrm{abs}}\left(\log \varepsilon_{\max }\right)[\mathrm{nm}]$} & \multicolumn{2}{|c|}{$\lambda_{\max }^{\mathrm{em}_{\max }}\left(\Phi_{\mathrm{f}}\right)^{d}[\mathrm{~nm}]$} \\
\hline & & Toluene $^{b}$ & Thin film $^{c}$ & Toluene & Thin film ${ }^{c}$ \\
\hline 7 & 6.4 & & & 0.37) & \\
\hline & 11.9 & ), 323 (4.29) & 458 & $585(0.2$ & 635 \\
\hline \multicolumn{6}{|c|}{ 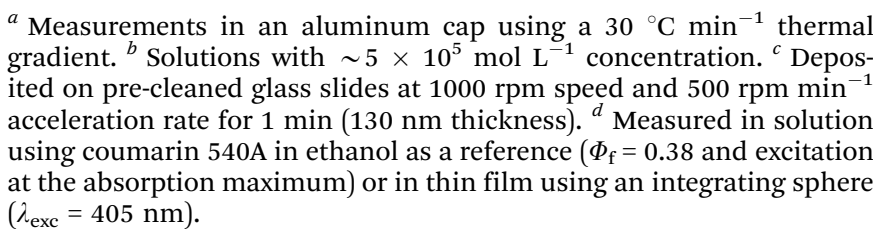 } \\
\hline
\end{tabular}

two overlapping bands at $370 \mathrm{~nm}$ and $354 \mathrm{~nm}$ for 7 , and two well-distinct bands at 458-452 $\mathrm{nm}$ and $323 \mathrm{~nm}$ for 8 (Fig. 1 and Table 1). The absence of significant broadening or energy shift when passing from solution to solid thin films demonstrates weak $\pi-\pi$ packing in the ground state due to steric repulsion induced by the bulky substituents.

By comparison with very similar compounds, the electronic transitions lying at lower energy could be ascribed to strong HOMO-LUMO charge transfer between the amino core (where the HOMO electronic density is mainly spread) and the electronwithdrawing groups supporting the LUMO electronic distribution. The higher energy bands would result from a HOMO-LUMO+1 charge transfer along the biphenylamino branches. ${ }^{17}$ The emission spectra in thin films underwent notable bathochromic shift compared to those in solution with fluorescence signals peaking at $635 \mathrm{~nm}$ for 8 (against $585 \mathrm{~nm}$ in solution) and $495 \mathrm{~nm}$ for 7 (against $465 \mathrm{~nm}$ in solution) (Table 1). The fluorescence quantum yields $\Phi_{\mathrm{f}}$ using an integrating sphere for solid state measurements were valued at 0.36 for both compounds processed as thin films. No drop in the emission intensity when going from solution to thin films was thus observed for compound 7 whereas a significant increase was detected for compound $\mathbf{8}$ 

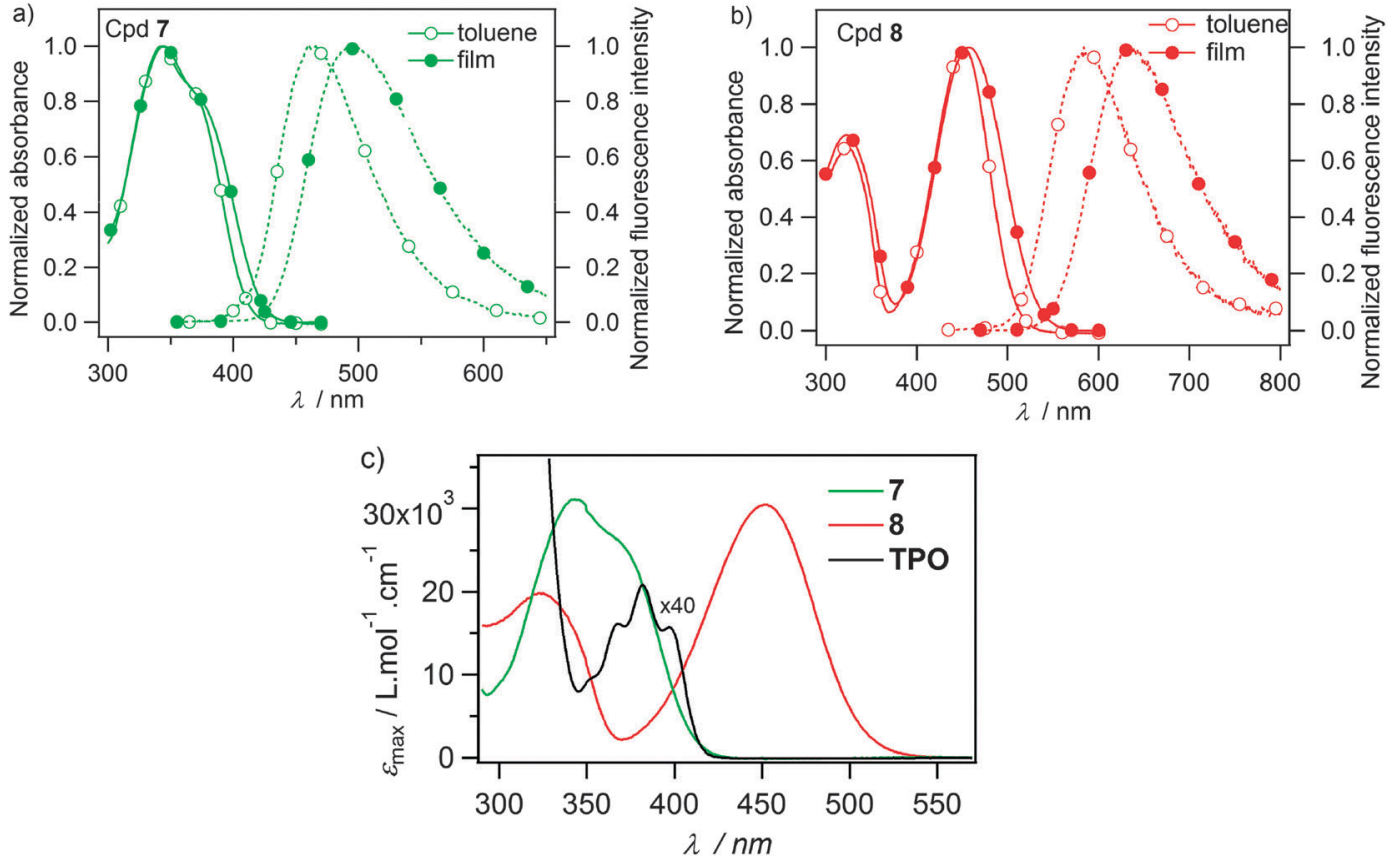

Fig. 1 UV-vis absorption (solid symbols) and emission spectra (empty symbols - excitation at the maximum absorption wavelength) of compounds 7 and 8: (a) in toluene solution $\left(5 \times 10^{-5} \mathrm{~mol} \mathrm{~L}^{-1}\right.$ ), (b) processed as thin films from a 1 wt\% solution in chloroform (thickness $\sim 130 \mathrm{~nm}$ ). (c) UV-vis absorption spectra of compound 7, compound 8 and photoinitiator TPO (magnified by a $\times 40$ factor) in toluene solution.

( $\Phi_{\mathrm{f}}$ in toluene was found at 0.29 ) as a result of restricted nonradiative processes provided by structural rigidification in the solid state. Formation of J-aggregates that is commonly evoked to explain the bathochromic shift and slight intensity increase of the emission signal does not operate here. We rather attribute the observed changes to strong polarity modification of the surroundings and restricted vibrational motions, known to severely affect the picosecond evolution of the populated excited state of each dye surrounded by polar homologues. ${ }^{18}$

\section{Photocrosslinking}

The solution-processed thin films were photopolymerized using diphenyl(2,4,6-trimethylbenzoyl)phosphine oxide (TPO) as a radical photoinitiator. ${ }^{19}$ Such photoinitiator undergoes fast homolytic $\alpha$-cleavage of the carbon-phosphorous bond under UV illumination, which gives rise to two short-lived triplet radicals $(\tau<1 \mathrm{~ns})$. As a consequence, the initiation process is faster than that encountered for most of the commercial photoinitiators, which is crucial to limit the risks of competitive energy transfer toward the emissive units. TPO excitation can indeed severely compete with excitation of fluorophore 8 that displays a lower energy red-emitting excited state. Such energy deactivation pathways might be one of the reasons why photopolymerization of coupled red-emitters has never been reported to date. Moreover, irradiation of TPO could advantageously be conducted at $365 \mathrm{~nm}$, which is easily obtained from common mercury lamps, and occurred at the absorption minimum of compound $\mathbf{8}$, thereby minimizing energy loss upon energy transfer.

Photopolymerizable thin films were fabricated by spincoating solution mixtures in chloroform of monomer (7 or 8) and TPO (typical composition $1 \mathrm{wt} \% 7$ or 8 and TPO in $3 \mathrm{~mol} \%$ relative to compound, namely $1.5 \mathrm{~mol} \%$ to acrylate monomers). Film thickness between 50 and $150 \mathrm{~nm}$ was obtained depending on the rotation speed and acceleration during deposition. The film surface was found to be remarkably flat with a root mean square (RMS) roughness as low as $0.5 \mathrm{~nm}$ and $0.2 \mathrm{~nm}$ for compounds $\mathbf{7}$ and $\mathbf{8}$, respectively, namely similar to that of vacuum-deposited thin films. ${ }^{20}$ Photocrosslinking was carried out at $365 \mathrm{~nm}$ at room temperature while development was performed at room temperature by using chloroform as a solvent. In this way, the non-irradiated material was removed by a simple washing step with common organic solvents (chloroform being one of them). In contrast to oxetane photopolymerization requiring an ulterior step of curing at high temperatures to kill the living radical cations, no further temperature curing is needed, thereby avoiding mechanical stress on the structure. The concentration of the photoinitiator, the exposure dose and the atmosphere revealed to be essential parameters to control the thickness and emission efficiency of the remaining photocrosslinked material. Various assays showed an optimal TPO concentration of $3 \mathrm{~mol} \%$ for compound 7 and $5 \mathrm{~mol} \%$ for compound 8 , which represents quite low concentrations given the possible competitive energy absorption, especially for compound 7. Lower TPO concentration left insufficient photocrosslinked material after development whereas higher TPO concentration caused no further improvement (Fig. 2a). As for the exposure dose, the optimal value was found to be $6.3 \mathrm{~J} \mathrm{~cm}^{-2}$ to provide minimum photobleaching and maximum remaining thickness (Fig. 2b).

No significant improvement could be obtained upon heating the thin films during irradiation, which instead revealed to be detrimental and caused irreversible material dewetting. 

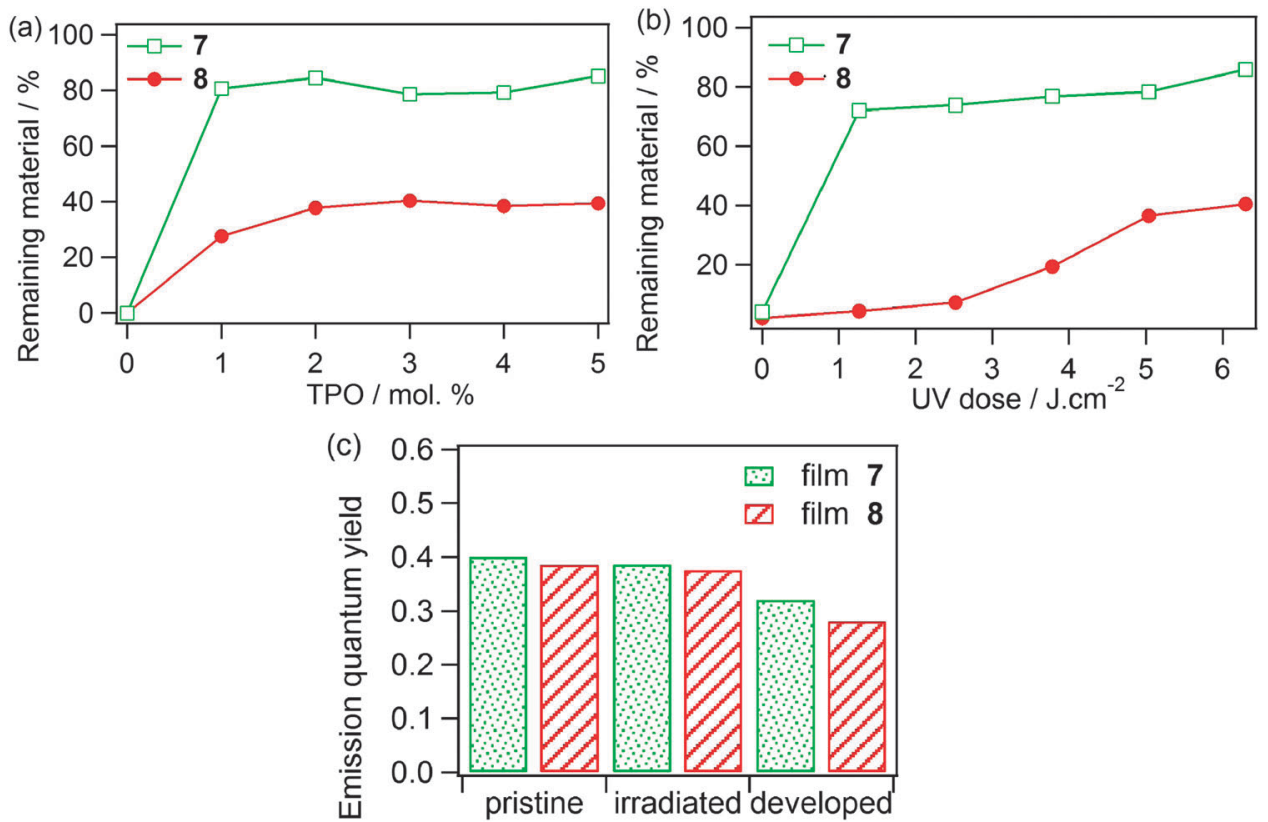

Fig. 2 Remaining material after photoirradiation at $365 \mathrm{~nm}$ and development with $\mathrm{CHCl}_{3}$ as a function of: (a) the exposure dose in $\mathrm{J} \mathrm{cm}^{-2}$ ( 3 mol\% and 5 mol\% TPO concentration regarding compound 7 and 8 respectively), (b) the TPO concentration (at a $6.3 \mathrm{~J} \mathrm{~cm}{ }^{-2}$ exposure dose). (c) Fluorescence quantum yields measured using an integrating sphere for pristine, photoirradiated and developed thin films 7 and 8 containing 3 mol\% TPO.

Furthermore, the impact of oxygen on photopolymerization is worth noting. As both films are very thin ( $100 \mathrm{~nm}$ thickness), oxygen diffusion is expected to occur quickly and deactivates radicals, compelling us to work under oxygen-free conditions. It is worth nothing that photopolymerization of compound 7 , contrary to compound $\mathbf{8}$, could be carried out in air. A higher energy dose of $6 \mathrm{~J} \mathrm{~cm}^{-2}$ (against $0.02 \mathrm{~J} \mathrm{~cm}^{-2}$ under oxygen-free conditions) was then required to yield equivalent thicknesses of the crosslinked material. ${ }^{21}$ Comprehensive photophysical investigations beyond the scope of the studies reported herein are currently carried out to interpret this difference in photoreactivity. All thin films remained highly fluorescent with an emission quantum yield measured in the solid state close to $75-80 \%$ of the initial value (after normalization to the remaining absorbance) (Fig. 2c). These values are quite remarkable given the recent studies carried out using photocrosslinkable iridium complexes and reporting significant photodegradation of the initial phosphorescent units. ${ }^{13 b}$ Photochemical degradations under UV irradiation are commonly evoked to explain the decrease in emission intensity. Such degradation can be clearly ruled out under the adopted conditions here since the final emission quantum yields correlate with the amounts of remaining material after development. This has been made possible by working in a glovebox under an inert atmosphere and by using a short irradiation time and a high power for a given thickness. The drop in emission quantum yield after development is likely to originate from very distinct surroundings around each photocrosslinked fluorophores compared to the situation before or after irradiation. Indeed, local microscopic properties like polarity or rigidity that largely differ after photocrosslinking are known to impact the radiative and non-radiative processes and thereby the emission quantum yields. By contrast, no change in the emission energy after development could be detected whatever the irradiation conditions. The conjugated part of the fluorophores, supporting the electronic density of the radiative excited state, is indeed unaffected by the formation of the single bonds between the acrylate units. It is worth noting that after photopolymerization and development, the emission intensity of the processed thin films remains stable over time. Almost no surface irregularities appeared after development since the RMS roughness measured by AFM remains remarkably weak at $0.2 \mathrm{~nm}$ and $0.7 \mathrm{~nm}$ for photopolymerized 7 and $\mathbf{8}$ materials (see ESI, $\dagger$ Fig. S2). These values are very close to those for pristine and irradiated thin films, showing that photopolymerization occurs quite homogeneously in the bulk and no molecular structuration or segregation operated before or after development.

We thus harnessed the high photoreactivity and surface quality of thin films made of 7 to fabricate sub-micrometric patterns using a pre-aligned photomask (Fig. 3a-c). The irradiation was performed in air for $17 \mathrm{~min}$ at $365 \mathrm{~nm}$ at an irradiation power

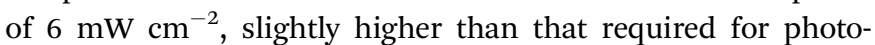
polymerization under an inert atmosphere as mentioned above.

After development and metallization, SEM images revealed very fine features down to $600 \mathrm{~nm}$-wide and $43 \mathrm{~nm}$-high (Fig. 3d and e). Z-profile measurements of the fine features using AFM show unexpectedly sharp edges with regard to the initially soft material (Fig. 3f). Another very interesting point concerns the SEM resolved images that displayed barbed patterns and very small dots in between. The random distribution of the latter lets us suggest a possible light scattering effect of the irradiation due to small molecular aggregates that could however not be detected by AFM measurements due to embedment in the fluorescent thin films. Another explanation could be related to light propagation during the illumination step as the fluorescent thin films act as 

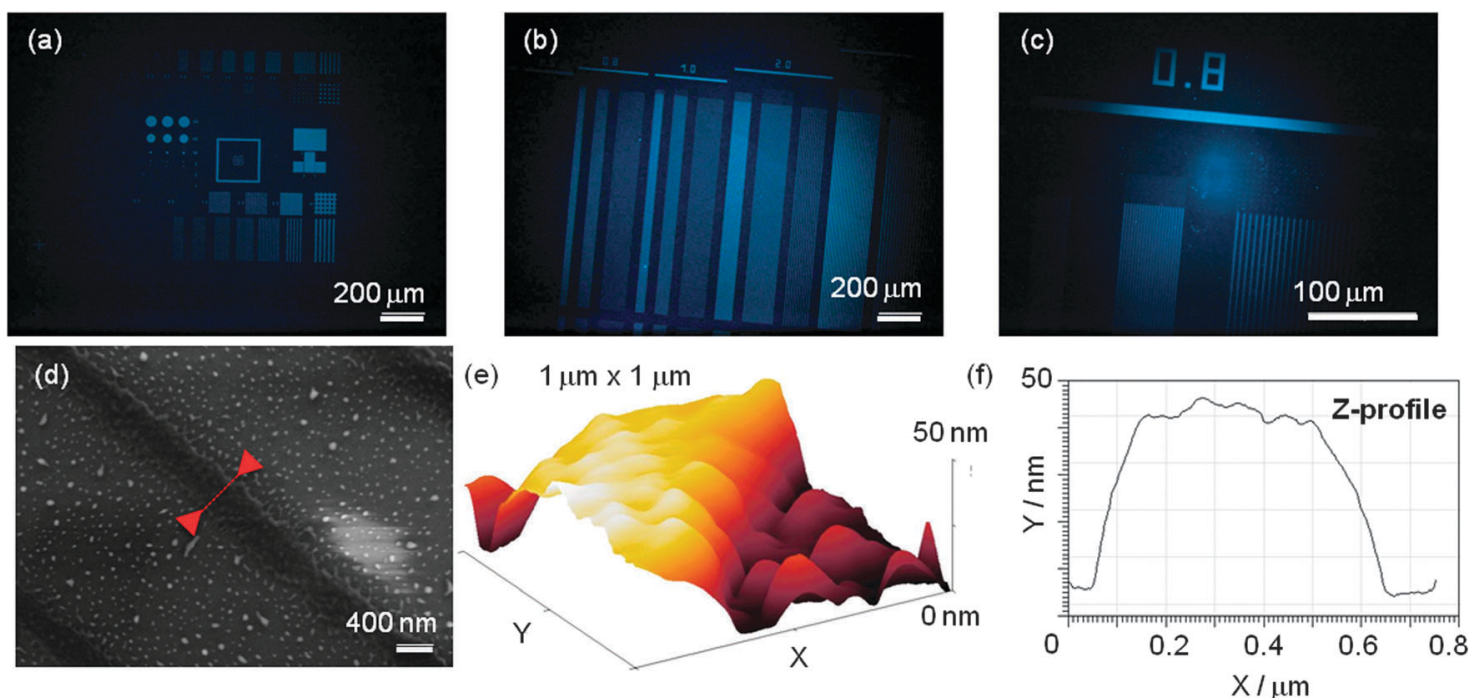

Fig. 3 Fluorescence images at $\lambda_{\mathrm{em}}=495 \mathrm{~nm}$ of thin films 7 photopatterned under an ambient atmosphere using home-made masks and illumination at $\lambda_{\text {exc }}=365 \mathrm{~nm}$ : (a) mask 1: $10 \times$ objective, (b) mask 2: $10 \times$ objective, (c) zoom of mask 2: $50 \times$ objective. SEM and AFM of the smallest features (0.8 bar pattern): (d) SEM image, (e) 3D-AFM image and (f) Z-profile.

a) UV lamp

UV lamp
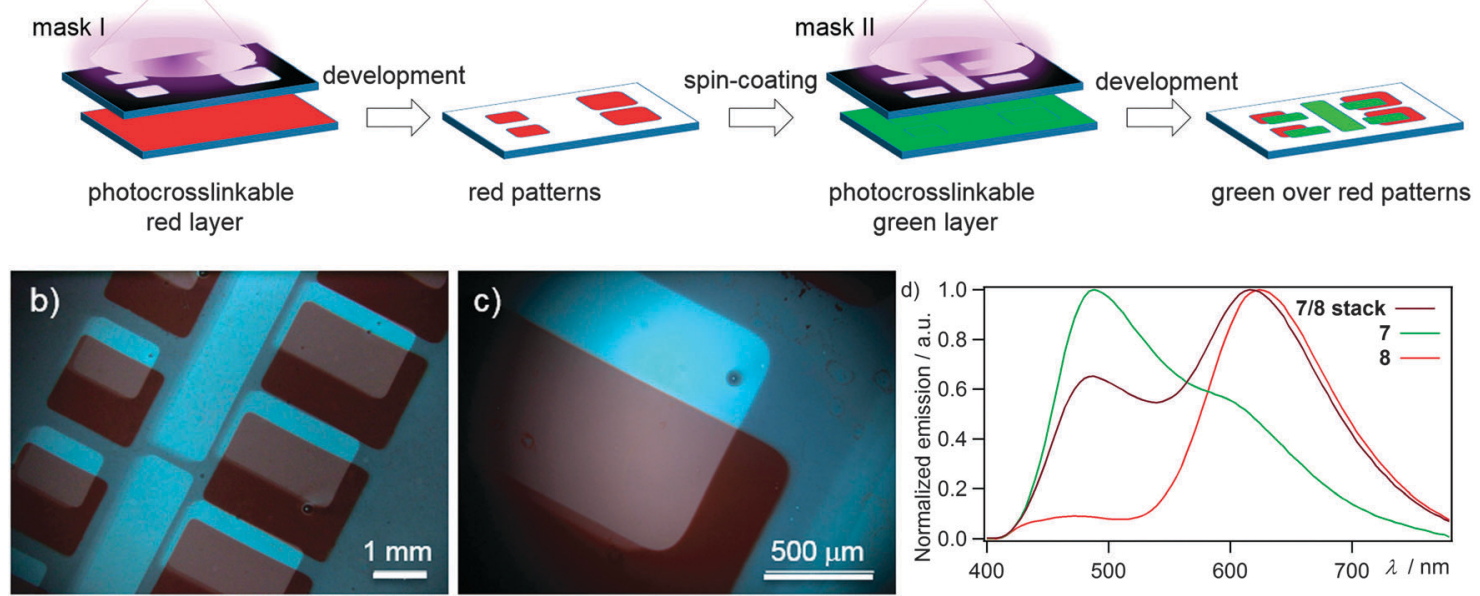

Fig. 4 (a) Schematic description of the two-step photolithography process using two distinct photomasks. Fluorescence imaging of green patterns (thickness $14 \mathrm{~nm}$ ) superimposed on pre-formed red-emitting patterns (thickness $7 \mathrm{~nm})(2 \mathrm{~mm} \times 2.5 \mathrm{~mm})$ after development using a: (b) $2.5 \times$ objective, (c) $10 \times$ objective. (d) Emission spectra of the green patterns, red patterns and superimposed green and red areas $\left(\lambda_{\text {irr }}=365 \mathrm{~nm}\right.$ ).

real light waveguides. Their presence proves the high adhesion on glass substrates of the patterned organic films, making their removal difficult even by mechanical scratch (spatula or nail), and thereby leading to quite mechanically stable printing.

\section{Multilayer emissive photopatterning}

To go further with the fabrication of multiple emissive layers that attract considerable interest in the field of multi-stacked devices like organic light emitting diodes, we first photocrosslinked a red emitting layer ( $45 \mathrm{~nm}$-thick) deposited on a glass substrate using a $1.6 \mathrm{~J} \mathrm{~cm}^{-2}$ exposure dose $\left(6.7 \mathrm{~mW} \mathrm{~cm}^{-2}\right.$ for $240 \mathrm{~s}$ ) (Fig. 4a and b). After development, a second layer of green material (50 nm-thick) was deposited and subjected to photoirradiation with a UV dose of $0.026 \mathrm{~J} \mathrm{~cm}^{-2}$ (namely
$1.7 \mathrm{~mW} \mathrm{~cm}^{-2}$ for $15 \mathrm{~s}$ ). Development of the final thin film revealed well-defined superimposed $7 \mathrm{~nm}$-thin red and $14 \mathrm{~nm}$-thin green patterns whose geometries followed the two-stage illumination patterns. The reduced thickness of the remaining thin films contrasts those obtained without using a mask. This stems from the very low energy dose used to obtain well-defined geometric patterns that would be blurred otherwise. The geometric average roughness $R_{\mathrm{q}}$ was measured to be $1.30 \mathrm{~nm}$ for the stack (see ESI, $\dagger$ Fig. S3). Interestingly, the development step considerably smoothens the surface since the initial red and green patterns displayed $R_{\mathrm{q}}$ equal to 1.93 and $2.15 \mathrm{~nm}$ respectively as a result of the intrinsic irregular surface of the glass substrate $\left(R_{\mathrm{q}}=2.02 \mathrm{~nm}\right)$. The emission spectra of the stacked area $7 / 8$ showed prevailing emission in the red region due to 
Förster resonance energy transfer made possible by strong overlap between the emission spectrum of 7 and the absorption spectrum of 8 (Fig. 4c). The small thickness of the green layer, close to the $10 \mathrm{~nm}$ distance limit for Förster dipole-dipole coupling, represents an additional factor, largely favoring such an energy transfer. Interestingly, neither pure green nor pure red emission could be obtained as a red or green contribution could be distinguished respectively. We again attributed these additional components to light waveguiding effects and not to materials remaining after development as the emission spectra were recorded from the whole substrate after exciting a specific spot of the processed substrate. Such observations could indeed be repeated at various locations and thus showed varying ratios of green and red emission signals. These subtle waveguiding effects permitted by the high surface quality of the polymerized thin films could be harnessed to obtain tunable emission over a large range of wavelengths by using a single stack of emitters.

\section{Conclusions}

In summary, a series of emitters strongly fluorescent and photopolymerizable in the solid state has been fabricated following a modular strategy. The incorporation of flexible acrylate chains allowed for the generation of insoluble emissive thin films upon cross-linking, with very high optical quality and great emission signal. Photocrosslinking of multicolored stacks has been successfully validated, yielding well-defined structures after development. Patterns down to $600 \mathrm{~nm}$-wide could be obtained by employing a mask aligner, which represents to our knowledge the highest resolved patterns using small molecule-based materials and simple one-photon irradiation. They appeared remarkably sharp given the very soft initial consistency of the organic materials and stuck firmly to the glass, making the printing very resistant to mechanical scratches. These innovative photopatternable emissive materials would find considerable application in the fields of organic electronics and photonics where solution-processed technologies represent cost-effective printing approaches, adaptable to any kind of substrates with various shapes or dimensions.

\section{Experimental}

\section{General methods and synthesis}

All chemical reagents and solvents were purchased from commercial sources (Aldrich, Acros, SDS) and used as received. Spectroscopic grade solvents purchased from Aldrich were used for spectroscopic measurements. All air-sensitive reactions were performed under argon using a vacuum line. Analytical TLC was performed on Kieselgel F-254 precoated plates. Visualization was done using a UV lamp. Flash chromatography was carried out with silica gel 60 (230-400 mesh) from SDS and 4-bis(4'-tertbutylbiphenyl-4-yl)aminobenzaldehyde was synthesized according to literature procedures. ${ }^{15}{ }^{1} \mathrm{H}$ NMR and ${ }^{13} \mathrm{C}$ NMR were recorded on Bruker $300 \mathrm{MHz}$ or $400 \mathrm{MHz}$ spectrometers. Chemical shifts $\delta$ were reported in ppm relative to TMS and referenced to the residual solvent. Low-resolution mass (LR-MS) spectra were obtained by electrospray ion trap mass spectrometry (LC-Esquire, Bruker) in positive-ion mode. High-resolution mass (HR-MS) spectra were obtained either by electrospray ionization coupled with high resolution ion trap orbitrap (LTQ-Orbitrap, ThermoFisher Scientific,) or by MALDI-TOF-TOF (Autoflex III de Bruker), both working in ion-positive mode.

(1-(4-Bromophenyl)ethoxy)(tert-butyl)dimethylsilane 1. Imidazole (5 g, $74 \mathrm{mmol}, 3.5$ eq.) was added to a solution of 4-bromo- $\alpha$ methylbenzyl alcohol (5 g, $25 \mathrm{mmol}, 1$ eq.) and dimethylaminopyridine (DMAP) (catalytic amount) in anhydrous DMF $(10 \mathrm{~mL})$. After complete imidazole dissolution, tert-butyl-dimethylsilyl chloride ( $4.5 \mathrm{~g}, 30 \mathrm{mmol}, 1.2 \mathrm{eq}$.) was further added. After stirring for 2 days at room temperature, the reaction mixture was diluted with dichloromethane. The organic layer was extracted and washed four times with brine, dried over anhydrous $\mathrm{Na}_{2} \mathrm{SO}_{4}$, and concentrated under vacuum. The resulting pale yellow oil was purified by Kugelrohr distillation, which provided compound 1 as a colorless oil (7.43 g, $23.5 \mathrm{mmol}, 94 \%) .{ }^{1} \mathrm{H}$ NMR $\left(\mathrm{CDCl}_{3}, 300 \mathrm{MHz}\right), \delta(\mathrm{ppm}): 7.42(\mathrm{~d}, J=8.5 \mathrm{~Hz}, 2 \mathrm{H}), 7.20(\mathrm{~d}, J=$ $8.5 \mathrm{~Hz}, 2 \mathrm{H}), 4.81$ (q, $J=6.3 \mathrm{~Hz}, 1 \mathrm{H}), 1.37$ (d, $J=6.4 \mathrm{~Hz}, 3 \mathrm{H}), 0.89$ (s, 9H), 0.04 (s, 3H), -0.04 (s, 3H). ${ }^{13} \mathrm{C} \mathrm{NMR}\left(\mathrm{CDCl}_{3}, 75 \mathrm{MHz}\right), \delta$ (ppm): 146.0, 131.2, 127.0, 120.4, 70.3, 27.2, 25.8, 18.1, -2.9, -4.9. Anal. calcd for $\mathrm{C}_{14} \mathrm{H}_{23}$ BrOSi. $0.15 \mathrm{CH}_{2} \mathrm{Cl}_{2}$ : C 51.81, H 7.16; found: C 51.9, H 6.77.

(4-(1-((tert-Butyldimethylsilyl)oxy)ethyl)phenyl)boronic acid 2. A solution of compound 1 ( $3.1 \mathrm{~g}, 9.84 \mathrm{mmol}, 1 \mathrm{eq}$.) in anhydrous THF $(20 \mathrm{~mL})$ was cooled to $-78{ }^{\circ} \mathrm{C}$ under argon. An $n$-butyllithium solution in hexane $(1.6 \mathrm{M}, 8 \mathrm{~mL}, 12.8 \mathrm{mmol}, 1.3 \mathrm{eq}$.) was added dropwise under argon over $30 \mathrm{~min}$. After stirring for $1 \mathrm{~h}$ at $-78{ }^{\circ} \mathrm{C}$, triisopropyl borate ( $9 \mathrm{~mL}, 39.4 \mathrm{mmol}, 4$ eq.) was added dropwise. The solution was slowly warmed up to room temperature over $3 \mathrm{~h}$ and stirred at room temperature for $1 \mathrm{~h}$. Excess of $n$-BuLi was neutralized by adding a $1 \mathrm{M} \mathrm{HCl}$ solution until $\mathrm{pH}=$ 3-4. The organic layer was washed twice with brine, dried over anhydrous $\mathrm{Na}_{2} \mathrm{SO}_{4}$, and concentrated under vacuum. The resulting colorless oil 2 was used without further purification $(2.71 \mathrm{~g}$, $9.54 \mathrm{mmol}, 97 \%) .{ }^{1} \mathrm{H} \mathrm{NMR}\left(\mathrm{CDCl}_{3}, 300 \mathrm{MHz}\right), \delta(\mathrm{ppm}): 8.19$ $(\mathrm{d}, J=8.1 \mathrm{~Hz}, 2 \mathrm{H}), 7.47(\mathrm{~d}, J=7.9 \mathrm{~Hz}, 2 \mathrm{H}), 4.95(\mathrm{q}, J=6.3 \mathrm{~Hz}, 1 \mathrm{H})$, $1.46(\mathrm{~d}, J=6.4 \mathrm{~Hz}, 3 \mathrm{H}), 0.93(\mathrm{~s}, 9 \mathrm{H}), 0.08(\mathrm{~s}, 3 \mathrm{H}), 0.00(\mathrm{~s}, 3 \mathrm{H}) .{ }^{13} \mathrm{C}$ NMR ( $\left.\mathrm{CDCl}_{3}, 75 \mathrm{MHz}\right), \delta$ (ppm): 151.7, 135.6, 124.8, 70.9, 27.2, 25.9, 18.3, -4.8 .

4-(Bis(4'-(1-((tert-butyldimethylsilyl)oxy)ethyl)-[1,1'-biphenyl]4-yl)amino)benzaldehyde 3. A solution of 4-di(4-bromophenyl)aminobenzaldehyde (195 mg, $0.46 \mathrm{mmol}, 1 \mathrm{eq}$.), tris-o-tolylphosphine (29 $\mathrm{mg}, 97 \mu \mathrm{mol}, 21 \% \mathrm{~mol}$ ) and palladium acetate(II) (7 mg, $32 \mu \mathrm{mol}, 7 \% \mathrm{~mol})$ in toluene ( $9 \mathrm{~mL}$ ) was thoroughly deoxygenated and stirred for $2 \mathrm{~min}$ under argon at room temperature. A solution of arylboronic acid 2 (326 mg, $1.16 \mathrm{mmol}, 2.5$ eq.) in deoxygenated methanol $(2 \mathrm{~mL})$ was subsequently added, followed by potassium hydroxide (160 mg, $2.8 \mathrm{mmol}, 6$ eq.) in water $(1 \mathrm{~mL})$. The reaction mixture was heated overnight at $70{ }^{\circ} \mathrm{C}$ under an inert atmosphere. After cooling to room temperature, the extracted organic layer was washed twice with brine, dried over $\mathrm{MgSO}_{4}$, and concentrated under vacuum. Compound $\mathbf{3}$ was obtained as a yellow solid after purification by silica gel chromatography using petroleum ether: dichloromethane 1:4 as an eluent (260 mg, $0.35 \mathrm{mmol}, 76 \%$ ). 
${ }^{1} \mathrm{H}$ NMR $\left(\mathrm{CDCl}_{3}, 300 \mathrm{MHz}\right), \delta(\mathrm{ppm}): 9.84(\mathrm{~s}, 1 \mathrm{H}), 7.72(\mathrm{~d}, J=$ $8.7 \mathrm{~Hz}, 2 \mathrm{H}), 7.58$ (d, $J=8.6 \mathrm{~Hz}, 4 \mathrm{H}), 7.55$ (d, $J=8.2 \mathrm{~Hz}, 4 \mathrm{H}), 7.40$ $(\mathrm{d}, J=8.2 \mathrm{~Hz}, 4 \mathrm{H}), 7.25(\mathrm{~d}, J=8.3 \mathrm{~Hz}, 4 \mathrm{H}), 7.13(\mathrm{~d}, J=8.8 \mathrm{~Hz}, 2 \mathrm{H})$, $4.92(\mathrm{q}, J=6.5 \mathrm{~Hz}, 2 \mathrm{H}), 1.44(\mathrm{~d}, J=6.3 \mathrm{~Hz}, 6 \mathrm{H}), 0.92(\mathrm{~s}, 18 \mathrm{H}), 0.07$ $(\mathrm{s}, 6 \mathrm{H}), 0.00(\mathrm{~s}, 6 \mathrm{H}) \cdot{ }^{13} \mathrm{C} \mathrm{NMR}\left(\mathrm{CDCl}_{3}, 75 \mathrm{MHz}\right), \delta$ (ppm): 190.6, 153.3, 146.3, 145.3, 138.7, 137.9, 131.5, 129.5, 128.3, 126.7, 126.4, 125.9, 120.0, 70.7, 27.4, 26.0, 18.4, -4.64. HR-MS (MALDI-TOF) $m / z:[\mathrm{M}]^{+}$calcd for $\mathrm{C}_{47} \mathrm{H}_{59} \mathrm{NO}_{3} \mathrm{Si}_{2}$ 742.4106; found 742.4133.

4-(Bis (4'-(1-hydroxyethyl)-[1,1'-biphenyl]-4-yl)amino)benzaldehyde 4. A solution of compound 3 (280 mg, $0.38 \mathrm{mmol}, 1$ eq.) in anhydrous tetrahydrofuran $(10 \mathrm{~mL})$ and tetrabutylammonium fluoride ( $1 \mathrm{~mL}, 1 \mathrm{M}, 2.6 \mathrm{eq}$.) was stirred overnight at room temperature under argon. The solution was washed twice with brine, and the organic layer was dried over anhydrous $\mathrm{MgSO}_{4}$, before solvent removal under vacuum. The crude product was purified by silica gel chromatography using petroleum ether: ethyl acetate $1 / 1$ as an eluent to give compound 4 as a yellow solid (180 mg, $0.35 \mathrm{mmol}, 92 \%) .{ }^{1} \mathrm{H} \mathrm{NMR}\left(\mathrm{CDCl}_{3}, 300 \mathrm{MHz}\right), \delta$ (ppm): $9.84(\mathrm{~s}, 1 \mathrm{H}), 7.73(\mathrm{~d}, J=8.8 \mathrm{~Hz}, 2 \mathrm{H}), 7.60(\mathrm{~d}, J=3.9 \mathrm{~Hz}$, $4 \mathrm{H}), 7.57$ (d, $J=4.2 \mathrm{~Hz}, 4 \mathrm{H}), 7.46$ (d, $J=8.2 \mathrm{~Hz}, 4 \mathrm{H}), 7.27$ (d, $J=$ $8.4 \mathrm{~Hz}, 4 \mathrm{H}), 7.15$ (d, $J=8.7 \mathrm{~Hz}, 2 \mathrm{H}), 4.97$ (q, $J=6.3 \mathrm{~Hz}, 2 \mathrm{H}), 1.55$ $(\mathrm{d}, J=6.5 \mathrm{~Hz}, 6 \mathrm{H}) .{ }^{13} \mathrm{C} \mathrm{NMR}\left(\mathrm{CDCl}_{3}, 75 \mathrm{MHz}\right), \delta(\mathrm{ppm}): 190.5$, $153.1,145.3,144.9,139.5,137.5$, 131.4, 129.5, 128.3, 127.0, 126.3, 125.0, 120.1, 70.2, 25.2. HR-MS (MALDI-TOF) $\mathrm{m} / \mathrm{z}:[\mathrm{M}]^{+}$ calcd for $\mathrm{C}_{35} \mathrm{H}_{31} \mathrm{NO}_{3}$ 513.2298; found 513.2293.

2-(4-(Bis (4'-(1-hydroxyethyl)-[1,1'-biphenyl]-4-yl)amino)benzylidene)malononitrile 5 . To a solution of compound 4 (2.22 g, $4.32 \mathrm{mmol}, 1 \mathrm{eq}$.) in anhydrous pyridine (35 mL) and glacial acetic acid $(21 \mathrm{~mL})$ a catalytic amount of ammonium acetate was added, followed by malononitrile $(600 \mathrm{mg}, 9.7 \mathrm{mmol}$, 2 eq.). The reaction mixture was stirred overnight at room temperature under argon. After addition of a $1 \mathrm{M} \mathrm{HCl}$ solution $(30 \mathrm{~mL})$, the red solid was filtered off, and washed with a $1 \mathrm{M} \mathrm{HCl}$ solution and distilled water. The red solid was dissolved in dichloromethane, and the resulting solution was dried over anhydrous $\mathrm{MgSO}_{4}$, before solvent removal under vacuum to give compound $\mathbf{5}$ as a pure deep red solid (2.38 g, $4.23 \mathrm{mmol}, 98 \%) .{ }^{1} \mathrm{H} \mathrm{NMR}\left(\mathrm{CDCl}_{3}, 300 \mathrm{MHz}, \delta\right)$ : $7.78(\mathrm{~d}, J=9.0 \mathrm{~Hz}, 2 \mathrm{H}), 7.61(\mathrm{~d}, J=6.0 \mathrm{~Hz}, 4 \mathrm{H}), 7.58(\mathrm{~d}, J=5.5 \mathrm{~Hz}$, $4 \mathrm{H}), 7.54(\mathrm{~s}, 1 \mathrm{H}), 7.47$ (d, J= 8.2 Hz, 4H), 7.29 (d, J = 8.5 Hz, 4H), 7.08 (d, $J=9.0 \mathrm{~Hz}, 2 \mathrm{H}), 4.97$ (q, $J=6.4 \mathrm{~Hz}, 2 \mathrm{H}), 1.55$ (d, $J=6.5 \mathrm{~Hz}, 6 \mathrm{H})$ ppm. ${ }^{13} \mathrm{C} \mathrm{NMR}\left(\mathrm{CDCl}_{3}, 75 \mathrm{MHz}, \delta\right): 157.9,153.2,145.1,144.3,141.8$, 139.2, 138.6, 133.1, 128.5, 127.1, 126.8, 126.0, 123.2, 119.1, 75.9, 70.1, 25.2 ppm. HR-MS (MALDI-TOF) $m / z$ : $[\mathrm{M}]^{+}$: calcd for $\mathrm{C}_{38} \mathrm{H}_{31} \mathrm{~N}_{3} \mathrm{O}_{2}$ 561.2411; found 561.2429.

4-(2-(Acryloyloxy)ethoxy)-4-oxobutanoic acid 6. A solution of 2-hydroxyethylacrylate $(6 \mathrm{~mL}, 52.3 \mathrm{mmol}, 1 \mathrm{eq}$.) and triethylamine (10 mL, $72.3 \mathrm{mmol}, 5$ eq.) was added dropwise to a solution of succinic anhydride (26.2 g, $262 \mathrm{mmol}, 5$ eq.) in anhydrous dichloromethane $(200 \mathrm{~mL})$, previously placed under an inert atmosphere. After stirring for $12 \mathrm{~h}$ at room temperature, the reaction mixture was washed twice with aqueous $3 \mathrm{M}$ $\mathrm{HCl}$ solution, dried over anhydrous $\mathrm{MgSO}_{4}$, and concentrated under vacuum. The resulting brown oil was diluted in diethylether and placed at $0{ }^{\circ} \mathrm{C}$ for $1 \mathrm{~h}$. Solid impurities were removed upon filtration to give pure compound $\mathbf{6}$ as a clear brown oil after concentration under vacuum (9.16 g, $40.4 \mathrm{mmol}, 81 \%$ ).
This compound is stabilized by addition of a catalytic amount of hydroquinone. ${ }^{1} \mathrm{H} \mathrm{NMR}\left(\mathrm{CDCl}_{3}, 300 \mathrm{MHz}, \delta\right): 6.44(\mathrm{~d}, J=$ $17.3 \mathrm{~Hz}, 1 \mathrm{H}), 6.14$ (dd, $J=17.3,10.4 \mathrm{~Hz}, 1 \mathrm{H}), 5.87$ (d, $J=10.4 \mathrm{~Hz}$, $1 \mathrm{H}), 4.36(\mathrm{~m}, 4 \mathrm{H}), 2.68(\mathrm{~m}, 4 \mathrm{H}) \mathrm{ppm} .{ }^{13} \mathrm{C} \mathrm{NMR}\left(\mathrm{CDCl}_{3}, 75 \mathrm{MHz}, \delta\right)$ : 177.0, 171.9, 165.9, 131.5, 127.9, 62.5, 62.1, 28.7, 28.7 ppm. MS (ESI) $m / z:[\mathrm{M}+\mathrm{Na}]^{+}$calcd for $\mathrm{C}_{9} \mathrm{H}_{12} \mathrm{O}_{6} \mathrm{Na} 239.0526$; found 239.0522.

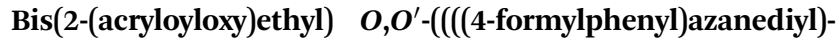
bis([1,1'-biphenyl]-4',4-diyl))bis(ethane-1,1-diyl))disuccinate 7 . A solution of compound 4 (1.42 g, $2.76 \mathrm{mmol}, 1 \mathrm{eq}$.), dimethylaminopyridinium $p$-toluenesulfonate (DPTS) $(811 \mathrm{mg}, 2.76 \mathrm{mmol}$, 1 eq.) and compound 6 (2.39 g, $11 \mathrm{mmol}, 4$ eq.) in anhydrous dichloromethane $(30 \mathrm{~mL})$ was placed under an inert atmosphere and cooled down to $0{ }^{\circ} \mathrm{C}$. A solution of dicyclocarbodiimide (DCC) $(1.7 \mathrm{~g}, 8.26 \mathrm{mmol}, 3 \mathrm{eq}$.) previously diluted in anhydrous dichloromethane $(5 \mathrm{~mL})$ was then added dropwise. The resulting mixture was left under stirring at room temperature for $12 \mathrm{~h}$. After filtration of the solid impurities and concentration of the solution under vacuum, the resulting crude product was dissolved in toluene $(\sim 1-3 \mathrm{~mL})$ and filtered to remove undissolved urea. After concentration of the solution, purification of the white solid was performed by silica gel chromatography using dichloromethane as an eluent to yield the photopolymerizable green emitter 7 as a pale green oil (1.6 g, $1.76 \mathrm{mmol}, 64 \%)$. ${ }^{1} \mathrm{H} \mathrm{NMR}\left(\mathrm{CDCl}_{3}, 300 \mathrm{MHz}, \delta\right): 9.84(\mathrm{~s}, 1 \mathrm{H}), 7.73(\mathrm{~d}, J=8.8 \mathrm{~Hz}$, $2 \mathrm{H}), 7.56(\mathrm{~m}, 8 \mathrm{H}), 7.42(\mathrm{~d}, J=8.2 \mathrm{~Hz}, 4 \mathrm{H}), 7.26(\mathrm{~d}, J=8.6 \mathrm{~Hz}, 4 \mathrm{H})$, $7.14(\mathrm{~d}, J=8.7 \mathrm{~Hz}, 2 \mathrm{H}), 6.43(\mathrm{dd}, J=17.3,1.5 \mathrm{~Hz}, 2 \mathrm{H}), 6.13(\mathrm{dd}, J=$ $17.3,10.4 \mathrm{~Hz}, 1 \mathrm{H}), 5.94(\mathrm{q}, J=6.6 \mathrm{~Hz}, 2 \mathrm{H}), 5.85$ (dd, $J=10.4$, $1.5 \mathrm{~Hz}, 1 \mathrm{H}), 4.33(\mathrm{~m}, 8 \mathrm{H}), 2.76-2.62(\mathrm{~m}, 8 \mathrm{H}), 1.58(\mathrm{~d}, J=6.5 \mathrm{~Hz}$, $6 \mathrm{H}) \mathrm{ppm} .{ }^{13} \mathrm{C} \mathrm{NMR}\left(\mathrm{CDCl}_{3}, 75 \mathrm{MHz}, \delta\right): 190.4,172.0,171.4$, 165.8, 153.0, 145.4, 140.5, 139.9, 137.3, 131.4, 131.3, 129.6, 128.3, 127.9, 126.9, 126.6, 126.2, 120.1, 72.5, 62.3, 62.1, 29.3, 28.9, 22.1 ppm. HR-MS (ESI) m/z: [M] $]^{+}$calcd for $\mathrm{C}_{53} \mathrm{H}_{51} \mathrm{NO}_{13}$ 910.3433; found 910.3422. UV-vis (toluene), $\lambda_{\max }\left(\varepsilon_{\max }\left(\mathrm{mol}^{-1} \mathrm{~L} \mathrm{~cm}^{-1}\right)\right)$ : $370(\mathrm{sh}), 345\left(3.10 \times 10^{4}\right) \mathrm{nm}, \lambda_{\mathrm{em}}\left(\Phi_{\mathrm{f}}\right): 465(0.37) \mathrm{nm}$.

Bis(2-(acryloyloxy)ethyl) $O, O^{\prime}-(((4-(2,2-d i c y a n o v i n y l) p h e n y l)-$ azanediyl)bis([1,1'-biphenyl $]-4^{\prime}, 4$-diyl $)$ )bis(ethane-1,1-diyl))disuccinate 8 . The procedure was identical to that reported for compound 7 except that the following solutions were used: solution of compound 5 (730 mg, $1.30 \mathrm{mmol}, 1$ eq.), DPTS (803 mg, $3.9 \mathrm{mmol}, 1 \mathrm{eq}$.$) , and compound 6$ (1.12 g, $5.2 \mathrm{mmol}, 4$ eq.) in anhydrous dichloromethane $(20 \mathrm{~mL})$, and solution of DCC ( $803 \mathrm{mg}, 3.9 \mathrm{mmol}, 3 \mathrm{eq}$.) in anhydrous dichloromethane $(2 \mathrm{~mL})$. Purification of the red power was performed by silica gel chromatography using petroleum ether/ethyl acetate $6 / 4$ as an eluent to provide compound 8 as a honey-like viscous red compound $(790 \mathrm{mg}, 0.82 \mathrm{mmol}$, $63 \%) .{ }^{1} \mathrm{H} \mathrm{NMR}\left(\mathrm{CDCl}_{3}, 300 \mathrm{MHz}, \delta\right): 7.78(\mathrm{~d}, J=9.0 \mathrm{~Hz}, 2 \mathrm{H})$, $7.62-7.52(\mathrm{~m}, 9 \mathrm{H}), 7.43(\mathrm{~d}, J=8.2 \mathrm{~Hz}, 4 \mathrm{H}), 7.28(\mathrm{~d}, J=8.2 \mathrm{~Hz}, 4 \mathrm{H})$, 7.08 (d, $J=9.0 \mathrm{~Hz}, 2 \mathrm{H}), 6.43(\mathrm{dd}, J=17.3,1.4 \mathrm{~Hz}, 2 \mathrm{H}), 6.13$ (dd, $J=17.3,10.4 \mathrm{~Hz}, 2 \mathrm{H}), 5.94(\mathrm{q}, J=6.6 \mathrm{~Hz}, 2 \mathrm{H}), 5.85(\mathrm{dd}, J=10.4$, $1.4 \mathrm{~Hz}, 2 \mathrm{H}), 4.39-4.29(\mathrm{~m}, 8 \mathrm{H}), 2.71-2.65(\mathrm{~m}, J=4.9 \mathrm{~Hz}, 8 \mathrm{H}), 1.58$ $(\mathrm{d}, J=6.8 \mathrm{~Hz}, 6 \mathrm{H}) \cdot{ }^{13} \mathrm{C} \mathrm{NMR}\left(\mathrm{CDCl}_{3}, 75 \mathrm{MHz}, \delta\right): 173.8,172.1$, 171.4, 165.9, 144.4, 140.8, 139.7, 139.6, 138.4, 133.0, 132.9, 131.5, 128.5, 127.9, 127.1, 126.8, 126.7, 123.3, 119.2, 72.5, 71.1, 62.4, 62.2, 29.4, 29.0, 22.2 ppm. HR-MS (MALDI-TOF) $\mathrm{m} / \mathrm{z}:[\mathrm{M}]^{+}$calcd for $\mathrm{C}_{56} \mathrm{H}_{51} \mathrm{~N}_{3} \mathrm{O}_{12}$ 957.3467; found 957.3498. UV-vis (toluene), 
$\lambda_{\max }\left(\varepsilon_{\max }\left(\mathrm{mol}^{-1} \mathrm{~L} \mathrm{~cm}^{-1}\right)\right): 452\left(3.02 \times 10^{4}\right), 323\left(1.95 \times 10^{4}\right) \mathrm{nm}$, $\lambda_{\text {em }}\left(\Phi_{\mathrm{f}}\right): 585(0.29) \mathrm{nm}$.

\section{Film coating and crosslinking}

Photopolymerizable solutions were prepared in chloroform and contained 1 wt $\%$ monomer and 0.014 wt $\%$ of TPO (4 mol\% relative to monomer). Thin films were prepared by spin-coating on glass slides the pre-filtered photopolymerizable solution using a PTFE filter (Millex ${ }^{\circledR}, 0.45 \mu \mathrm{m}$ ) placed on a $1 \mathrm{~mL}$ glass syringe, at a spin acceleration of $500 \mathrm{rpm} \mathrm{s}^{-1}$ and a rotation speed of $1000 \mathrm{rpm}$ for $60 \mathrm{~s}$. The resulting film thickness was measured to be around $130 \mathrm{~nm}$ by means of a mechanical profilometer (Dektak Veeco 8). Photocrosslinking was realized by illuminating the deposited thin film using a mercury light source (Hamamatsu Lightning Cure LC6 or OmniCure Series 2000) filtered at $365 \mathrm{~nm}$ with an exposure dose depending on the experimental conditions. The non-polymerized material was readily removed by washing out the samples with spectroscopic grade chloroform.

\section{Photophysical characterization}

UV-visible absorption spectra in toluene solution and in thin films were recorded using a Varian Model Cary 5E spectrophotometer, using an integrating sphere DRA 2500. Corrected emission spectra were obtained using a Jobin-Yvon. Inc. spectrofluorimeter (Fluorolog 2 ) and a $22^{\circ}$ front face mode was used for thin film emission measurements. Fluorescence quantum yields in solution were determined using Coumarin $540 \mathrm{~A}$ in EtOH $\left(\Phi_{\mathrm{f}}=0.38\right) .{ }^{22}$ Measurement of the emission quantum yield in the solid state was performed with the following experimental setup based on an earlier proposed design. ${ }^{23}$

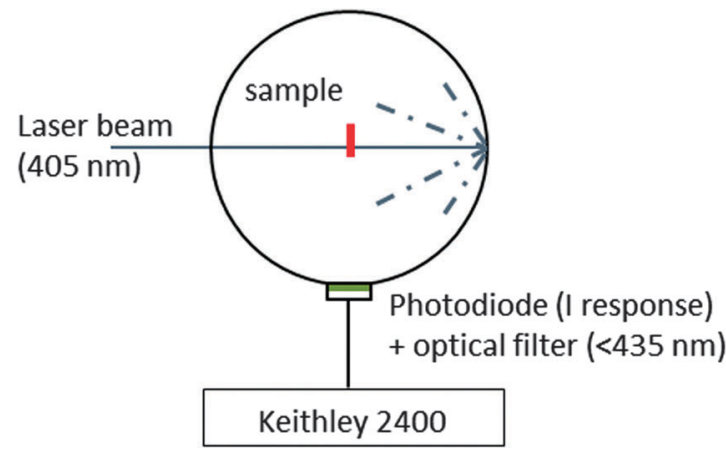

Three configurations were used for the efficiency measurement: (a) the integrating sphere is empty, (b) the sample is mounted in the sphere and the laser beam directed onto the sphere wall (c) the sample is mounted in the sphere and the laser is focused onto the sample. Each of these configurations was used with or without filter. The values are used to directly compute the absolute emission quantum yield of the emitting layer.

$$
\Phi_{\mathrm{f}}=\frac{P_{\mathrm{c}} L_{\mathrm{b}}-P_{\mathrm{b}} L_{\mathrm{c}}}{L_{\mathrm{a}}\left(L_{\mathrm{b}}-L_{\mathrm{c}}\right)}
$$

with $P$ and $L$ corresponding to the photo-current resulting from the emission of the sample and the emission from laser respectively, under various excitation conditions.

\section{AFM, SEM and fluorescence microscopy imaging}

Glass wafers made of Borofloat ${ }^{\circledR} 33$ were purchased from Schott and packaged by BT Electronics (50 $\mu \mathrm{m}$-thick). They were used as received. Sub-micropatterning was realized using a mask aligner MJB4 from Süss MicroTec working in a hard contact mode. The green and red multistack was realized under oxygen-free conditions using a glovebox Jacomex P [svs]-II-S and a mercury lamp Omni Cure series 2000 filtered at $365 \mathrm{~nm}$. Fluorescence imaging was performed using an optical microscope (Olympus BX51) equipped with a mercury lamp U-LH100HG and a fluorescence filter cube $\left(\lambda_{\mathrm{exc}}=330-385 \mathrm{~nm}\right.$ and $\left.\lambda_{\mathrm{em}}>420 \mathrm{~nm}\right)$ as an irradiation source. The fluorescence wide field images were captured using a CCD camera Infinity2-2 from Lumenera while the emission spectra were recorded using a SpectraScan PR-655 spectroradiometer from Photo Research. SEM imaging was performed using a Zeiss Ultra FE-SEM instrument. Topographic measurements were performed in the tapping mode using a Dimension 3100 (Veeco - Bruker) atomic force microscope.

\section{Acknowledgements}

Photolithography and SEM imaging were performed through The "Plateforme Technologique Amont" of Grenoble-LETI and financially supported by the "Nanosciences aux limites de la nanoélectronique” fundation and CNRS Renatech network.

\section{Notes and references}

1 (a) M. Irie, T. Fukaminato, T. Sasaki, N. Tamai and T. Kawai, Nature, 2001, 420, 759; (b) C. Corredor, Z.-L. Huang and K. D. Belfield, Adv. Mater., 2006, 18, 2910-2914.

2 (a) M. J. Hynes and J. A. Maurer, Mol. BioSyst., 2013, 9, 559-564; (b) Y. Fuchs, O. Soppera and K. Haupt, Anal. Chim. Acta, 2012, 717, 7-20.

3 (a) S. Chenais and S. Forget, Polym. Int., 2012, 61, 390-406; (b) L. M. Goldenberg, V. Lisinetskii, Y. Gritsai, J. Stumpe and S. Schrader, Adv. Mater., 2012, 24, 3339-3343.

4 C. D. Muller, A. Falcou, N. Reckefuss, M. Rojahn, V. Wiederhirn, P. Rudati, H. Frohne, O. Nuyken, H. Becker and K. Meerholz, Nature, 2003, 421, 829-833.

5 B. Duong, H. Liu, C. Li, W. Deng, L. Ma and M. Su, ACS Appl. Mater. Interfaces, 2014, 6, 8909-8912.

6 B. D. Gates, Q. Xu, M. Stewart, D. Ryan, C. G. Willson and G. M. Whitesides, Chem. Rev., 2005, 105, 1171-1191.

7 Z.-B. Sun, X.-Z. Dong, W.-Q. Chen, S. Nakanishi, X.-M. Duan and S. Kawata, Adv. Mater., 2008, 20, 914-919.

8 G. Jiang, S. Wang, W. Yuan, L. Jiang, Y. Song, H. Tian and D. Zhu, Chem. Mater., 2006, 18, 235-237.

9 C. A. Zuniga, S. Barlow and S. R. Marder, Chem. Mater., 2011, 23, 658-681.

10 Q. H. Cui, Y. S. Zhao and J. Yao, Adv. Mater., 2014, 29, 6852-6870.

11 M. C. Gather, A. Kohnen, A. Falcou, H. Becker and K. Meerholz, Adv. Funct. Mater., 2007, 17, 191-200. 
12 K. Iliopoulos, O. Krupka, D. Gindre and M. Sallé, J. Am. Chem. Soc., 2010, 132, 14343-14345.

13 (a) B. W. Ma, B. J. Kim, D. A. Poulsen, S. J. Pastine and J. M. J. Frechet, Adv. Funct. Mater., 2009, 19, 1024-1031; (b) G. Liaptsis, D. Hertel and K. Meerholz, Angew. Chem., Int. Ed., 2013, 52, 9563-9567.

14 L. Duan, L. Hou, T.-W. Lee, J. Qiao, D. Zhang, G. Dong, L. Wang and Y. Qiu, J. Mater. Chem., 2010, 20, 6392-6407.

15 E. Ishow, A. Brosseau, G. Clavier, K. Nakatani, P. Tauc, C. Fiorini-Debuisschert, S. Neveu, O. Sandre and A. Leaustic, Chem. Mater., 2008, 20, 6597-6599.

16 K. E. S. Snell, N. Stéphant, J.-F. Audibert, R. Pansu, F. Lagugné-Labarthet and E. Ishow, Langmuir, 2014, 30, 2928-2935.
17 E. Ishow, G. Clavier, F. Miomandre, M. Rebarz, G. Buntinx and O. Poizat, Phys. Chem. Chem. Phys., 2013, 15, 13922-13939.

18 E. Ishow, R. Guillot, G. Buntinx and O. Poizat, J. Photochem. Photobiol., A, 2012, 234, 27-36.

19 J.-P. Fouassier and J. Lalevée, Photoinitiators for Polymer Synthesis: Scope, Reactivity and Efficiency, Wiley-VCH, Weinheim, Germany, 2012.

20 S. Feng, L. Duan, L. Hou, J. Qiao, D. Zhang, G. Dong, L. Wang and Y. Qiu, J. Phys. Chem. C, 2011, 115, 14278-14284.

21 H. Nishi, T. Asahi and S. Kobatake, J. Photochem. Photobiol., A, 2011, 221, 256-260.

22 G. A. Reynolds and K. H. Drexhage, Opt. Commun., 1975, 13, 222-225.

23 J. C. de Mello, H. F. Wittmann and R. H. Friend, Adv. Mater., 1997, 9, 230-232. 